\title{
“Gerçeği Arayış” Filminin Mesleki Etik Prensipler Çerçevesinde Değerlendirilmesi
}

\author{
Meryem Karaaziz* \\ Yakın Doğu Üniversitesi \\ Hicran İnand1lar \\ Atatürk Üniversitesi \\ Özet
}

\begin{abstract}
"Gerçeği Arayış" filmi Adli Psikiyatri Bölüm Başkanı ve başarılı bir psikanalist olan Profesör Barr'ın hastasının ablasıyla kurduğu etik dışı romantik ilişkiyle başlayan talihsiz olaylar zincirini ele almaktadır. Dr. Barr'ın, terapisine devam ettiği hastasının bir gangsterle evli olan ablasına aşık olmasıyla tüm hayatı değişmiştir. Onunla yaşadığı aşk terapist kimliğini bir kenara itmesine ve gerçeği reddetmesine yol açmıştır. İlişkisinin ilerlemesiyle birlikte Dr. Barr kendini aşık olduğu kadın tarafından tuzağa düşürülmüş bir cinayet zanlısı olarak bulur. Film, Dr. Barr'ın mesleki etik prensipleri hiçe sayıp aşkını yaşamayı tercih etmesi ile birlikte kendisini bir tuzağın içinde bulmasını ve bu tuzaktan kurtuluşunu işlemektedir. Filmde etik prensiplere uymanın sadece hastayı değil aynı zamanda terapisti de nasıl koruduğu profosyonelce işlenmiştir
\end{abstract}

Anahtar Kelimeler: Gerçeği Arayış filmi, terapist, etik

*İletişim: meryem.karaaziz@gmail.com

Başvuru Tarihi: Mart 2016

Kabul Tarihi: Mayıs 2016 


\section{“Gerçeği Arayış” Filminin Mesleki Etik Prensipler Çerçevesinde Değerlendirilmesi}

\section{Filmin Konusu ve Değerlendirme}

Dr. Isaac Barr (Richard Gere) mesleğinde oldukça başarılı bir psikanalisttir ve Adli Psikiyatri Bölüm Başkanı olarak çalışmaktadır. Dr. Barr, mesleğine bağlı ve idealist bir terapisttir. Yeri geldiğinde hastalarından ücret bile almadan onlara terapi uygulamaktadır. Mesleğini hayatının merkezine koymuş bir terapist olan Dr. Barr hem kendi ofisinde psikoterapi uygulamalarında bulunmakta hem de adli psikiyatri uzmanı olarak mahkemelere bilir kişi olarak çağrılmakta, suçlular ile terapötik görüşmeler yapmaktadır. Maddi durumu kötü olan suçlularla olan görüşmelerde maddi bir talepte bulunmayarak mahkemeyi şaşırttığ 1 zamanlar çok olmuştur. Dr. Barr, çocukluk dönemine ait travmaları olan Diana (Uma Thurman) isimli bir hastayla psikanaliz seanslarına devam ederken, Diana'nın zengin bir gangster ile evli olan ablası Haether Evans'la (Kim Basinger) ile tanışır. Dr. Barr, karısından boşanmış, uzun zamandır romantik bir ilişki yaşamamış ve tek aşkı mesleği olmuş birisidir. Ancak, Heather ile karşılaştığı zaman hiç düşünmediği bir şekilde ondan etkilenir. Uzun zamandır mesleğinin gerekliliği dışında hiçbir kadınla iletişime girmeyen ve sosyal hayata yeterince katılmayan bir kişi olarak bir kadının onunla ilgilenmesinden etkilenmesi oldukça beklendiktir. Heather güzel, alımlı ve çekicidir. Aynı zamanda, gangster kocası tarafindan hem fiziksel şiddete hem de sözel aşağılanmalara maruz kalan ve eğer ayrılmaya kalkarsa öldürüleceği korkusuyla yaşayan mutsuz ve aciz bir kadındır. Dr. Barr'ın da Heather'ın kendisini bir kurban gibi sunan tavırlarının etkisinden kaçabilmesi mümkün olmamıştır.

Beyaz perdede terapist figürünün çoğunlukla sorunlu insanların kurtarıcısı rolünde gösterildiği görülmektedir. Bununla birlikte, Yalom'a göre terapistler, kendilerine her zaman doğrunun söylendiğine inandıkları için en kolay kandırılabilecek kişilerdir (Yalom, 2002). Heather'ın gangster kocasından korkup nefret etmesine karşın boşanamamasından da ayrıca etkilenen terapist kendisini birden onu kurtarma fantazisi içerisinde bulur. Terapist bu duygusunu fark eder ve arkadaşları ile paylaşır. Buradaki esas mesele terapistin bunu fark ettiği noktada geri çekilmemesi ve devam etmesidir. Arkadaşları kendisini büyük bir hata yaptığı ve etik anlamda da büyük bir yanlışın içerisinde olduğu yönündeki uyarmalarına karşın o duygularına yenik düşer. Masum bir etkilenmenin de ilerisine geçerek flörtleşme ve hatta cinsel birliktelik yaşanır. Daha sonra Heather'ın "patolojik sarhoşluk" (pathological intoxication) isimli, bilimsel anlamda varlığı tam olarak kanıtlanamamış, uzmanların varlığı üzerine tartıştığı bir soruna sahip olduğu ortaya çıkar. Bu sorun, çok az miktarda alkol alınması halinde bile kontrolsüz davranışlar sergilenmesine yol açan ve sonrasında bu kontrolsüz davranışların hatırlanmaması ile kendini gösteren bir durumdur.

İlişkileri süreç içerisinde ilerlemiştir. Daha sık görüşmeye başlayan terapist ile Heather, bu günlerden birinde Dr. Barr için özel olan bir deniz fenerine giderler. Bu esnada Heather'ın çantasından demir bir el halteri (dambıl) düşer. Terapist bunu eline alır ve böylece parmak izlerini bunun üzerinde bırakmış olur. Heather yanında dambıl taşımasını kendisini korumak için bir önlem olarak açıklar. Daha sonra ise terapistin parmak izlerinin bulunduğu dambıl ile kocasının kafasına vurarak onu öldürür. Dr. Barr bu olay üzerine Heather'ı "patolojik sarhoşluk" tanısı ile hapiste yatmaktan kurtarmaya çalışır. Burada da terapistin kurtarıcı rolünün bir kez daha gündeme geldiği söylenebilir. Terapist, onu kurtarmak için elindeki tüm kaynakları seferber eder. Dr. Barr'ın en yakın dostlarından birinin avukat, diğerinin ise patolojik sarhoşluk konusunda gazetede yazısı çıkan başarılı bir terapist olması Heather'ın işini oldukça kolaylaştırmıştır. Bu sıralarda, katıldığı bir konferansta bir rüya ve Freud'un bu rüyayı analizi Dr. Barr'ın oldukça dikkatini çeker, çünkü seanslarından birinde, Diana da bu rüyadaki temaları kendisine tıpatıp kendi rüyası olarak anlatmıştır. Aslında bu olay Dr. Barr için sarsıcı olmuştur bile denilebilir, konferans terapistin bir düşten uyandığı yer oluvermiştir. Dr. Barr hemen kütüphaneye koşar ve durumu araştırır, rüyanın anlamı ile birlikte olayın gizemini de çözer. Hastası Diana ve tutkuyla bağlandığı kadın olan Heather kendisine bir komplo 
hazırlamışlardır. Terapist, bir de Heather'ın kocasını öldürdüğü halterin üzerinde kendi parmak izlerinin olduğunu duyması ile büyük bir şok yaşar. Terapist bunun üzerine aşk sarhoşluğundan uyanıp kendine gelmek durumunda kalır. Heather, onun için artık aşkla bağlandığı bir kadın değil ona tuzak kurup, onu kullanan ve tehdit eden bir kadındır. Bu nedenle, suç aletini geri almak ister. Ancak, bu alete ulaşmak kolay olmayacaktır.

Heather, Dr. Barr'ın yoğun çabaları, (daha öncede belirtildiği gibi) bu konuda yayını olan başka bir terapistin tanıklığı ve Dr. Barr'ın avukat arkadaşının savunmaları ile hapisten kurtulmayı başarmıştır. Tabii ki, tüm bunlar da tesedüf değildir. Heather tüm bunları hesaplayarak Dr. Barr'1 kardeşine terapist olarak seçmiş ve bu komployu hazırlamışlardır. Ancak, beklenmeyen şey kız kardeşi Diana'nın da terapistine aşık olmasıdır. Heather, hapisten kurtulmayı başarsa da mahkeme kararı ile kapalı bir psikiyatri servisinde gözetim altında tutulmaktan kurtulamamıştır. Bir süre gözetimin ardından Dr. Barr'ın da bulunduğu bir değerlendirme kurulunun karşısına çıkacaktır. Bu kez Dr. Barr, Heather'e bir tuzak kurar ve Diana'nın da yardımı ile onun paranoid şizofreni tanısı almasını sağlar. Bunu başarabilmek için Heather'a değerlendirme kurulu hakkında yanlış bilgi verir; mahkemeden gelen üyelerin kendisini bir kez daha mahkeme için değerlendireceklerini, kendisinin de zaten kurula olan biteni anlattığını söyler. Değerlendirme kurulundaki kişilere ise onun paranoid şizofreni semptomları gösterdiğini anlatır. Kurul günü Heather gelen kişileri mahkemeden ve olanı biteni bilen kişiler zanneder ve tüm suçu Dr. Barr'ın üzerine atacak şekilde bir senaryo yazarak anlatır. Son olarak ise kız kardeşinin suç aleti olan halteri getireceğini söyler ama kız kardeşi halteri getirmez. Ancak kuruldaki kişiler Heather'in söyledikleri ile kendi bildikleri arasında bağlantı kuramazlar. Bunun üzerine, Heather tam bir sinir krizi geçirir. Bağırıp çağırmaya, Dr. Barr ve kız kardeşine saldırıp şiddet davranışları sergilemeye başlar. Böylelikle kuruldaki kişiler onun paranoid şizofreni olduğuna ikna olur. Burada Dr. Barr terapist kimliği ile hareket ederek onun zayıf noktasını fark etmiş ve onu oradan vurmayı başarmıştır. Heather, Dr. Barr'ın kendisini uzun yıllar boyunca orada kalmasını sağlayacağını anlar. Diğer taraftan ise bu davranışı karşısında büyük bir hayal kırıklığı yaşadığı kız kardeşinin de kendisine özendiğini ve Dr. Barr'a aşık olduğunu farketmiştir. Bu durumun tek farkında olan Heather değildir, Dr. Barr da bu durumun farkındadır. Bu nedenle terapi seansları sırasında Heather'ın kız kardeşini kendi tarafına çeker ve halteri getirmesine engel olur. Daha sonra bir kafede halen hastası olan Diana ile buluşur. Ona, artık kendisiyle seanslara devam edemeyeceğini, terapiyi sonlandırması gerektiğini, seanslara devam etmenin etik olarak mümkün olmayacağını bunun yanısıra analisti olarak da kendisine faydalı olamayacağını düşündüğünü, onun için yapabileceği en doğru şeyin onu iyi bir terapiste yönlendirmek olduğunu açıklar. Terapist ve hasta ilişkisinin bir gerçekçi tarafı, bir de gerçek dışı tarafı olduğu bilinmektedir. İlişkinin gerçekçi tarafı sorunu çözümlemeye yönelik süreçtir. Bu sürecin kilidi hastanın çocukluk çağında gelişen temel güven duygusu ve terapistin hastasına saygı duymasıyla, onu koşulsuz kabul ettiğini hissettirmesiyle oluşan terapötik işbirliğidir. Psikoterapide çok yakın bir ilişski kurulur ve hasta kimsenin bilmediği çok özel duygularını paylaşır, oysa terapist kendisi ile ilgili çok sınırlı bilgi verir. Bu durum hastanın terapiste yönelik fanteziler kurgulamaya başlamasına neden olabilir. Tam da bu noktada ilişkinin gerçek dışı tarafı gelişmeye başlar; hasta ebeveynlerine ya da onların yerine geçen kişilere hissettiği duyguları ve dilekleri terapistine yönlendirir. Bu duruma ise aktarım adı verilir (Özmen, 2008). Diana ve Dr. Barr arasında da böyle bir aktarım gözlemlenmektedir. Diana da Dr. Barr'a hep hayal ettiği "kurtarıcı baba" rolünü yüklemiş ve onunla olma fantazileri kurmuştur. Dr. Barr biraz geç de olsa bu aktarımı fark etmiştir. Burada dikkat çeken diğer bir nokta da, terapistin bu kadar olaydan sonra etiğin hem terapisti hem hastayı koruduğunun (Korkut, 2014) farkındalığına erişmesi ve gereken davranışı sergilemesidir. Dr. Barr, Diana'dan dambılı ister ancak o, dambılı denize attığını söyleyerek (yalan söyleyerek) vermeyi reddeder ve kendisini oldukça değersiz hisseder. Bu sahnede bir diğer dikkat çekici faktör kısa saçlı olan Heather'ın kız kardeşinin saçlarını ablasınınkinin boyuna getirmiş olması, giyim tarzı ve davranışlarını da ona benzetmeye çalışmasıdır. Kardeş rekabeti ile literatürde de sıkça karşılaşılmaktadır. Özellikle küçük olanın büyük olana 
özenmesi ve onun gibi davranışlar sergilemeyi arzulaması beklendiktir (Brenner, 1998). Burada da benzer bir durum söz konusudur. Ablasıyla romantik bir ilişki yaşayan Dr. Barr'ın kendisiyle romantik bir ilişki yaşamayı reddetmesi, terapötik bir ilişkiye son vermek istemesi onu oldukça yaralar ve suç aletini ona vermeyi reddeder. Bu duygularla birlikte kendini iyice yalnız hisseder ve hayattaki tek varlığı olan ablasıyla dertleşmek için ablassının bulunduğu hastaneye onu ziyarete gider. Dış görünüşlerinin çok benzer hale geldiğini fark eden Heather'ın aklına hemen bir fikir gelir, yer değişirler. Bu şekilde Herther hastaneden kaçmayı başarır. Amacı suç aletini dedektife vererek suçu Dr. Barr'ın üzerine yıkmaktır. Bu sırada Dr. Barr, kendisine daha önceden ücretsiz psikoterapi hizmeti verdiği bir hastasından Heather'ın kız kardeşini takip etmesini, o haltere ulaşmasını rica eder. Eski danışan halteri Heather'in boş bir anını yakalayarak ondan çalmayı başarır. Ancak, tam Dr. Barr'a ulaştırmak üzereyken Heather tarafindan silahla vurularak yaralanır, Heather dambilı geri alır.

Heather da boş durmamış paranoid şizofreni olmadığını ispatlamak ve cinayeti de Dr. Barr’a yıkmak için halteri Dr. Barr'dan hoşlanmayan ve Heather davasında ona inanmayan bir dedektife vermek için onunla anlaşmıştır. Dedektif deniz kenarında başka bir olayla ilgili çalışırken Heather ona telefonla ulaşır ve bulunduğu yeri öğrenip oraya gider. Ancak Dr. Barr'ın eski danışanı Heather ve dedektifin konuşmasını duymuştur ve ambulansa bindirilirken yanına yetişen Dr. Barr'a onların yerini söyler. Dr. Barr koşarak Heather ve dedektifin buluştuğu yere gider. Heather dambılı tam dedektife vereceği esnada dambıla dokunmayı başarır. Artık Dr. Barr dedektifin gözü önünde dambıla dokunduğundan parmak izlerinin olması onu suçlu pozisyonuna sokmayacaktır. Heather bu duruma oldukça öfkelenir. Dedektifle birlikte Dr. Barr'1 öldürmek için kaçırmaya çalışırken bir kaza geçirirler. Dr. Barr kazadan kurtularak deniz fenerine doğru kaçar, bu esnada sarsılmanın şiddetiyle baygınlık geçiren Heather da kendine gelir ve Dr. Barr'ın peşine düşer. Dedektif ise arabada baygındır. Dr. Barr çok kritik bir anda (Heather onu deniz fenerinde silahla vurarak öldürmek üzereyken) onun bu davranışını analiz eder. Heather'a alkolik babası tarafından bir çok kez tecavüze maruz kalan kişinin aslında kendisi olduğunu (Dr. Barr'a bu duruma maruz kalanın kız kardeşi olduğunu söylemişti) ve kocasının da kendisine zulmederek ona zarar verdiğini ancak tüm bunların geride kaldığını söyleyerek onu rahatlatmaya ve ölümden kurtulmaya çalışır. Bununla birlikte babasını içki içip sızdığı gecelerden birinde bir kibrit yakarak, eşini ise dambılı kafasına vurarak öldürdüğünü, onların belki de bunu hak ettiğini söyleyerek Heather'I sakinleştirmeye çalışır. Ancak o an dedektif sarsıntının sersemliğini üzerinden atmış ve deniz fenerine girmiştir. Bu arada dedektif yanlışlıkla bir yere çarpar ve ses çıkar, $b$ uses Heather'ın kendisine gelmesine yol açar. Heather, Dr. Barr'I öldürmek için tekrar hamle yapmaya çalışırken kendisi deniz fenerinden aşağı düşerek ölür. Dr. Barr ve dedektif ise birbirlerine yardımcı olarak deniz fenerinden aşağı inmeyi başarırılar.

\section{Sonuç}

Çocukluk ve ergenlik döneminde istismara maruz bırakılmak değişik etnik gruplarda, sosyoekonomik düzeylerde ve kültürlerde görülmektedir (Benner Carson 1996, Beck ve ark. 2003). Çocuğun veya ergenin sağlıklı bir biçimde gelişimini engelleyen her türlü eylem ileriki yaşamının bu travma eşliğinde sürdürülmesine neden olmaktadır. Bu tarz eylem veya eylemsizliklerin sonucu olarak çocuğun fiziksel, ruhsal, cinsel ya da sosyal olarak zarar görmesi, sağlık ve güvenliğinin tehlikeye girmesi oldukça mümkündür. Çocuk istismarı fiziksel, cinsel veya duygusal istismar olarak, çocuk ihmâli ise fiziksel veya duygusal ihmâl olarak ayrılmaktadır (Bulut 1996, Taner ve Gökler 2004). Burada Heather'in babası tarafından cinsel istismara uğramış olmasının o dönemde babasına ve diğer erkeklere karşı büyük bir öfke birikimine yol açtı̆̆ 1 ve bu öfkenin saldırganlıkla birleşerek "cinayet" yoluyla boşaltılmaya çalışıldığ düşünülebilir. Babasına olan öfkesini onu öldürmekle bile çözümlemeyi başaramayan Heather, bu öfkeyi başka erkeklere de yansıtarak onlar üzerinden güç ve para elde etmeye çevirdiği düşünülmüştür. Diğger bir 
deyişle Heater, istismar edilen konumundan istismar eden konumuna geçerek güç kazanmaya çalışmaktadır. Bu durumu analitik açıdan yorumlayacak olursak Heather, "yansıtmalı özdeşim" ve "yer değiştirme" gibi savunma mekanizmalarını kullanmaktadır. Gerçek öfke nesnesi baba olmasına karşın bu öfkenin hedefi değişerek eşi, terapist ve diğer erkekler olmuştur. Bu durumda "yer değiştirme" savunma mekanizmasını kullanmıştır. Heather' in bu zarar vermeye olan arzusu ve kendi öfkesini ancak bu şekilde boşaltarak doyuma ulaşması da tıpkı babasının var oluşuna benzemektedir. Bu noktada ise devreye "yansıtmalı özdeşim" savunma mekanizması girmektedir (Öztürk, 2011).

Özellikle çocukluk dönemine âit ruhsal etkiler uzun süre devam etmektedir. Örselenme deneyiminin sıklığı ve şiddeti ile psikopatolojinin de sıklığı ve şiddeti doğru orantılıdır (Özen ve ark. 2004). Burada da Heather'in babası tarafından yapılan cinsel istismar tüm hayatını olumsuz yönde etkileyerek patolojik bir örüntü sergilemesine zemin hazırlamıştır.

Travmanın şiddeti ve sıklığı değişse de her çocuk travmaya maruz kalarak yetişme riski ile doğar ve büyür (Sefa, 2007). Ancak burada önemli olan kişinin bu travma ile nasıl baş edebildiğidir. Heather'in baş etme yöntemi kendisine ve çevresine oldukça zarar vericidir. Ancak, filmdeki terapistin de bu kadına yem olabileceğini gösteren yaşantıları mevcuttur. Heather, neden bu adamı seçmiştir? Bu bir tesadüf değildir. Uzun gözlemler sonucu bu adamı seçmiş ve planını uygulamaya koymuştur. Yapılan araştırmalar, özellikle çocukluk çağında maruz kalınan şiddet, istismar ve ihmal gibi olumsuz yaşam olaylarının çocuk üzerinde derin izler bıraktığını ve bununla birlikte akıl ve ruh sağlığına zarar verici etkiler yarattığını ortaya koymaktadır (Yalçın, 2011).

İzleyicide bırakılan etki terapistin etik davranmaya çalışırken kendi kişisel zaafları ve çözümleyemediği problemleri sebebiyle etik ihlaller yapmaya müsait olduğu yönünde olmuştur. Dr. Barr duygularını farkettiği halde Heather'dan uzaklaşamamıştır. Bu noktada terapistin etik ikilem yaşadığı ve sonrasında ise bu ikilemi çözmedeki yetersizliğinden dolayı hem Amerikan Psikoloji Birliği (APA), hem Avrupa Psikologlar Birliği Federasonu (EFPA) hem de Türk Psikologlar Derneği (TPD) etik yönetmeliğine göre etik ihlallerde bulunduğu gözlemlenmiştir (Köse, 2007). Etik ihlal, terapistte ve diğer taraflarda ciddi rahatsızlık, çatışma ve hasarın ortaya çıkması ile meydana gelmektedir (Korkut, 2014). Örneğin; terapistin EFPA'nın "yetkinlik-yeterlilik" başlığı altındaki "etik farkındalık" prensibine göre etik konular ile mesleki uygulamayı bütünleştiremediği (EFPA 2005) düşünülmektedir. TPD’ye göre ise etik yönetmeliğin "yararlı olmak ve zarar vermemek" ilkesindeki "çoklu ilişkilere girmeme" kuralı Dr. Barr tarafından açık bir biçimde ihlâl edilmiştir (TPD, 2004).

TPD etik yönetmeliğinin "yararlı olmak ve zarar vermemek" ilkesindeki "psikolog, bilgi, statü ve sahip olduğu gücü kullanarak; kendi yararları doğrultusunda danışanların, ... emeklerini ve finansman kaynaklarını kullanamaz" kuralını çiğneyerek, sömürücü davranış sergilemiştir (TPD, 2004). EFPA'ya göre ise "dürüstlük" başlığı altındaki "çıkar çatışması ve kötüye kullanım” ilkesi çiğnenmiştir (EFPA, 2005). Terapistin danışanlarını veya eski danışanlarını kendi işlerini halletmesi için kullanmasının hiçbir şekilde etik olmadığı bir gerçektir.

Psikologların etik davranmalarını sağlamak amacıyla çeşitli yöntemler mevcuttur. Bunlardan en yaygını kurulan birlikler (APA, TPD, EFPA, vb.). 1şı̆̆ında psikoteröpatik sürecin ilerletilmesidir. Bu birlikler tarafından yayınlanan etik yönetmelikler mesleki anlamda psikologların/terapistlerin doğru olanı yapmalarını, yaptıkları herhangi bir işin sonuçlarını değerlendirmelerini, herhangi bir koşulda nasıl davranmaları gerektiğini belirten prensiplerden meydana gelmektedir (Türk Psikologlar Derneği, 2004; Knapp \& Vandecreek, 2010). Toplum içerisindeki bütün meslek gruplarının kendilerine özgü etik ilkeleri ve standartları olduğu gibi psikologların da/psikoterapinin de etik kuralları vardır. Doğan ve Tekinalp'e (2002) göre meslek etiğinin temel amacı, genelde toplumu ve özelde meslek elemanlarını, meslekleriyle ilgili olarak eğitmek ve bilinçlendirmektir. Ayrıca, hizmetin sunulduğu bireyleri, meslek elemanlarının etik olmayan uygulamalarından korumak da önemli bir amaçtır. Sözü edilen amaçlara yönelik olarak da, Kuçuradi’ye 
(1988) göre dünyanın neresinde olursa olsun, aynı meslekte çalışan bireylerin bu davranış kurallarına uygun davranmaları gerekmektedir (Ergene, 2004). Bu öyküdeki en büyük hata terapistin hem hastayı hem de kendisini korumasını sağlayacak etik kuralların farkında olmasına karşın duygularına yenik düşerek etik ihlalleri yinelemesidir diyebiliriz.

Sonuç olarak, belki de izleyicide bırakılmak istenen etki psikologların/terapistlerin de zayıf noktaları olabileceği, bunların farkında olmadıklarında hastalarını onlara zarar verme pahasına kullanabildikleri olabileceği düşünülmüştür. "Her terapistin bir terapisti vardır" sözü halk arasında olumsuz bir söylem gibi aktarılsa da, aslında tüm insanların terapiye ihtiyacı olabileceği gibi, terapistlerin de daha kaliteli ve farkındalıklı bir hayat sürmek için terapiye ihtiyaçları olabileceği görmezden gelmemek lazım. Terapiye gitmenin bir zayıflık değil bir güç olduğu farkındalığına erişmiş bir toplum olabilmek adına belki de sinemada bu tarz filmlere daha çok ihtiyacımız vardır. 


\section{Kaynaklar}

American Psychological Association (2002). Ethical Principles of Psychologists and Code Of Conduct. American Psychologist, 57(12), 1060-1073.

American Psychological Association (2010). Ethical Principles of Psychologists and Code of Conduct, Erişim Tarihi, Mayıs 2015, http://www.apa.org/ethics/code/principles.pdf.

Beck, S.E., Jackson, J.L., Fitzgerald, M., et. al. (2003). Child Abuse \& Neglect, 27: 1259-1275.

Benner, C. V. (1996). Mental Health Nursing the Nurse-Patient Journey. USA: WB Sounders Company, 1039-1075.

Brenner, C. (1998). Psikanaliz ve Temel Kavramları. (I. Savaşır ve Y. Savaşır, Çev.). Ankara: HYB Yayıncilik.

Bulut, I. (1996). Genç Anne ve Çocuk İstismarı. Ankara: 12-15.

Doğan, S. \& Tekinalp, B. E. (2002). Lisans düzeyinde Meslek Sorunları ve Ahlak İlkeleri dersinin kapsam ve işlenişi: Gazi Üniversitesi örneği. Psikolojik Danışmanlıkta Etik Sempozyumu Kitapçığı. 8-9 Haziran

Ergene, T. (2004). Psikolojik Danışmada Etik İlkeler: Etik Karar Verme Süreci. Eğitim Araştırmaları Dergisi, 4,15: 49-53.

European Federation of Psyhoclogists' Association (2005). Meta-Code of Ethics. Erişim Tarihi, Mayıs 2015, http://www.efpa.eu/ethics/meta-code-of-ethics.

Korkut, Y. (2002). Ülkemizde ruh sağlığı ile ilgili tüm branşlarda meslek etiği gerekliliği: etik ilke ve standartlar konusunda gelinen ve gelinmesi arzu edilen nokta üzerine düşünceler. Psikolojik Danışmanlıkta Etik Sempozyumu Kitapçı̆̆ı. 8-9 Haziran.

Korkut, Y. (2014). Psikologlar Iç̧in Etik Öğretim El Kitabı. Ankara: Türk Psikologlar Derneği Yayınları.

Köse, B. (2007). Panel: Sinemada Psikoterapistler ve Psikoterapi Etiği. Türk Psikoloji Bülteni, 41.

Knapp, S. J. \& Vandecreek, L. D. (2010). Psikologlar Için Pratik Etik (çev. : Y1lmaz, M., Karahan, T.F., Balcı Çelik, S. \& Sardoğan, M. E.). Ankara: Mentis Yayıncılık.

Öztürk, O. \& Uluşahin, A. (2011). Ruh Să̆lı̆̆ Ve Bozuklukları II. Ankara: Nobel Tıp Kitabevleri.

Özmen, M. (2008). Psikoterapiler. İ.Ü. Cerrahpaşa Tıp Fakültesi Sürekli Tıp Eğitimi Etkinlikleri, 62, 303322.

Sefa, B. (2007). Çocuk cinsel istismarı hakkında bir derleme. Türk Psikoloji ve Danışma Dergisi, 3(28).

Taner, Y.\& Gökler, B. (2004). Çocuk istismarı ve ihmâli: psikiyatrik yönleri. Hacettepe Tıp Dergisi, 35: $82-86$.

Türk Psikologlar Derneği (2004). Türk Psikologlar Derneği Etik Yönetmeliği. Erişim Tarihi, Mayıs 2015, http://www.psikolog.org.tr/turkey-code-tr.pdf

Yalçın, N. (2011). Türkiye'de Çocuk İstismarı ve Çözüm Önerileri. Yayınlanmamış Yüksek lisans tezi, Beykent Üniversitesi, İstanbul.

Yalom, D. (2002). Divan. (Ö. Arıkan, Çev.). İstanbul: Ayrıntı Yayınları. 


\section{Summary \\ Evaluation of the movie "'Final Analysis ' according to the concept of work ethics}

In the movie, 'Final Analysis' a psychiatrist named Dr. Barr who is the professor and the head of the criminal psychiatry department, has an non-ethical romantic relationship with his patient's sister. Dr Barr's Life starts to change when he develop a relationship with his patient's sister who is married to a gangster. The affair he has leads him to reject the responsibilities he has as a therapist. With his relationship is improved, Dr Barr founds out that his romance made him to fall in to a trap which he finds himself as a murder suspect. The movie is all about Dr Barr's decision about choosing his love over his work ethics. That is why, he founds himself in a trap and has been deceived by the woman he loves. However, he eventually manages to protect himself from this deception. In this movie we vitness how complying with the ethical principles protect the therapisthis rigts as much as the patients.

Keywords: "Final Analysis", therapist, ethic. 